\title{
Improving the Functionality of Dictionary Definitions for Lexical Sets: The Role of Definitional Templates, Definitional Consis- tency, Definitional Coherence and the Incorporation of Lexical Conceptual Models
}

Piet Swanepoel, Department of Afrikaans and Theory of Literature, University of South Africa, Pretoria, South Africa (swaneph@unisa.ac.za)

\begin{abstract}
This article focuses on some of the problems raised by Atkins and Rundell's (2008) approach to the design of lexicographic definitions for members of lexical sets. The questions raised are how to define and identify lexical sets, how lexical conceptual models (LCMs) can support definitional consistency and coherence in defining members of lexical sets, and what the ideal content and structure of LCMs could be.

Although similarity of meaning is proposed as the defining feature of lexical sets, similarity of meaning is only one dimension of the broader concept of lexical coherence. The argument is presented that numerous conceptual lexical models (e.g. taxonomies, folk models, frames, etc.) in fact indicate, justify or explain how lexical items cohere (and thus form sets). In support of Fillmore's (2003) suggestion that definitions of the lexical items of cohering sets should be linked to such explanatory models, additional functionally-orientated arguments are presented for the incorporation of conceptual lexical models in electronic monolingual learners' dictionaries. Numerous resources exist to support the design of LCMs which can improve the functionality of definitions of members of lexical sets. A few examples are discussed of how such resources can be used to design functionally justified LCMs.
\end{abstract}

Keywords: DEFINITIONAL TEMPLATES, DEFINITIONAL CONSISTENCY, DEFINITIONAL COHERENCE, LEXICAL CONCEPTUAL MODELS

Opsomming: Verbetering van die funksionaliteit van woordeboekdefinisies vir leksikale versamelings: Die rol van definisiematryse, definisie-eenvormigheid, definisiesamehang en die inkorporering van leksikale konseptuele modelle. Hierdie artikel fokus op sommige van die probleme wat ter sprake kom deur Atkins en Rundell (2008) se benadering tot die ontwerp van leksikografiese definisies vir lede van leksikale versamelings. Die vrae wat gestel word, is hoe leksikale versamelings gedefinieer en geïdentifiseer moet word, hoe leksikale konseptuele modelle (LKM's) definisie-eenvormigheid en 
-samehang kan ondersteun by die definiëring van lede van leksikale versamelings en wat die ideale inhoud en struktuur van LKM's sou kon wees.

Alhoewel betekenisooreenkoms as dié definiërende kenmerk van leksikale versamelings voorgestel word, is betekenisooreenkoms net een dimensie van die breër konsep van leksikale samehang. Die argument word aangevoer dat verskeie konseptuele leksikale modelle (bv. taksonomieë, lekemodelle, rame, ens.) in werklikheid aandui, motiveer of verduidelik hoe leksikale items saamhang (en dus versamelings vorm). Ter ondersteuning van Fillmore (2003) se voorstel dat definisies van die leksikale items van samehangende versamelings met sulke verduidelikende modelle gekoppel moet word, word bykomende funksioneel-georiënteerde argumente aangebied vir die inkorporering van konseptueel leksikale modelle in elektroniese eentalige aanleerderswoordeboeke. Talle bronne bestaan vir die ondersteuning van die ontwerp van LKM's wat die funksionaliteit van definisies van lede van leksikale versamelings kan verbeter. Enkele voorbeelde word bespreek van hoe sulke bronne aangewend kan word vir die ontwerp van funksioneel gemotiveerde LKM's.

Sleutelwoorde: DEFINISIEMATRYSE, DEFINISIE-EENVORMIGHEID, DEFINISIESAMEHANG, LEKSIKALE KONSEPTUELE MODELLE

\section{Introduction}

In arguing for the use of templates to define the meaning of words belonging to the same lexical set, Atkins and Rundell (2008: 124) provide the following two definitions from a learners' dictionary:

(1) lion ... a large strong African and Indian animal with four legs and light brown fur which eats meat and belongs to the cat family.

(2) tiger ... a large wild cat which has yellowish orange fur with black stripes.

The problem is, as they note, that both definitions refer to the animals' size, their fur, and their membership of the cat family. However, the definition for lion also provides information about diet, strength, number of legs, and habitat, which would be equally relevant features for the definition of tiger. This problem of inconsistency in defining members of lexical sets can be addressed, as the authors propose, by designing a definitional template, such as those in (3) and (4), as part of a larger template entry for the whole lexical set. Lexicographers can then design definitions for the cat/animal lexical set for a specific dictionary using the stipulated attributes/values as listed in the definitional templates in (3) and (4), bearing in mind the dictates of dictionary type, intended users and dictionary functions (Atkins and Rundell 2008: 125).

(3) LU meaning:

Domain $=$ zoology

The specific animal (species) 
a [size] [wild/domesticated] [carnivorous/herbivorous] mammal, Latin name XXX, having fur/hide [colour, markings], found in [habitat]. Also called XXX.

(4) LU meaning

Domain = zoology

The genus e.g. the cat family, the big cats

a [size] [wild/domesticated] [carnivorous/herbivorous] mammal, of the genus (LATIN NAME), such as the (SPECIES NAME), having fur/hide [colour, markings], found in [habitat]

In addition to the problem of definitional (in)consistency throughout a dictionary, definitions (1) and (2) illustrate another typical problem of many dictionaries, one which I will designate definitional (in)coherence. Definitional incoherence takes on a number of forms, but in (1) and (2) it is evident from the fact that lion is clearly indicated as being a member of the animal lexical set, while tiger is not. In this case, tiger is only identified as a member of the lexical set of large wild cats - a subdomain of the animal lexical set. Furthermore, the cohyponyms of tiger and lion are not mentioned in either of the definitions - not even the fact that they are cohyponyms of the same lexical set (i.e. of large cats). Apart from definitional inconsistency, there is thus also the problem of definitional incoherence in so far as it is not indicated what the members of lexical sets are and how they cohere (or in fact can be considered a lexical set). ${ }^{1}$ Lexical coherence is generally taken as a key organizing principle of the lexica of natural languages, and, as will be discussed below, needs to be addressed in dictionary definitions if they aim to support the functionality of such dictionaries.

Practical as the approach of Atkins and Rundell (2008) may be, these two problems are not, or not adequately, discussed by them, and some of the guidelines they provide for addressing these problems give rise to a number of questions that need further consideration.

The first of these is how the concept of "lexical set" should be defined and how lexical sets are to be identified in practice. Atkins and Rundell (2008: 128) mention that nearly sixty lexical sets were identified in a recent dictionary project which were amenable to template entry treatment, but they do not indicate how these lexical sets were derived and what the criteria for set membership was or how these criteria themselves were derived. This leads to the following question:

(a) How can you define and identify a lexical set in a language? (definition of the object; methodology of identification)

The second problematic aspect is the assumption that definitional consistency (in the choice of definitional features and their structuring) for the lexical items in a set results in more functional definitions, keeping in mind that functionality in dictionary terms is a multidimensional concept (cf. the discussion in Sec- 
tion 3). Although a lexical template such as (3) provides a basis for the construction of definitions for specific users, dictionary types and functions, it is an empirical question whether or not definitional consistency for the lexical items in a set will indeed improve the functionality of these definitions. For example, does one have to use specific attributes/values from template (3) for each of the possible functions that a learners' dictionary has to serve or will certain choices have an impact on the functionality of the definitions and others not? A simple example: Would the shorter definition of tiger (as in definition (2)) necessarily be less comprehensible and, for example, not assist a user in the interpretation of the meaning of the word in a text (two dimensions of functionality) than would an expanded definition which incorporates all the features listed in the definitional templates (3) and (4)? Whether or not definitional consistency in fact improves the functional quality of definitions is an empirical one, and one for which Atkins and Rundell (2008) provide no empirical backing by way of theory-driven empirical research. This leads to the following research question:

(b) Does definitional consistency improve the functional quality of dictionary definitions?

The next set of questions relate to the identification of lexical sets, the choice of defining attributes/values for a set, the structuring of such attributes/values in definitions, and the kind of justification one could provide for such choices:

(c) How do you decide what attributes and features are relevant for the definitions of the lexical items of a specific lexical set? (the question of methodology)

(d) Of all the possible attributes/values that could be used in the definitions of the lexical items in a set, which of these could/should you choose and on what do you base this decision? (the question of choice of content and justification for this choice)

(e) How do you structure the chosen definitional features, i.e. in what order do you present the attributes/values in the definition and why? (the question of structure)

(f) In what form do you present the defining attributes/values, i.e. what language do you choose to encode the attributes/values in the definition? (the question of form) (Cf. Atkins and Rundell 2008: 431-439 for an in-depth discussion of this issue.)

Limitations of space do not allow an in-depth discussion of all the issues raised by these questions. In Section 2 of this article, the focus falls on some of the problems raised by questions (a) and (c)-(e) and some of the solutions proposed by Atkins and Rundell (2008). As will be argued, although similarity of meaning is proposed as the defining feature of lexical sets, similarity of meaning is only one dimension of the broader concept of lexical coherence. The 
argument is raised that numerous conceptual lexical models (e.g. taxonomies, folk models, frames, etc.) (abbreviated to: LCMs) in fact indicate, justify or explain how lexical items cohere (and thus form sets). Following Fillmore's (2003) argument that the lexical items of cohering sets should be linked to such explanatory models, additional functionally-orientated arguments are presented in Section 3 for the incorporation of conceptual lexical models in electronic monolingual learners' dictionaries. In electronic dictionaries or webbased dictionaries, such linking mechanisms in definitions allow for the "spreading" of the required linguistic/conceptual knowledge required to understand, use or learn the meaning of members of lexical sets.

Given the fact that conceptual lexical models come in all shapes and sizes and often in human unfriendly formats, they have to be adjusted for human use. Section 4 provides an analysis of one such model.

\section{Lexical sets and their design features}

\subsection{Defining lexical set}

The problem of defining the term lexical set, like its often used synonym lexical domain, has a long history in lexical semantics (cf. Faber and Mairal Usón 1999; and Murphy and Medin 1985). Atkins and Rundell (2008: 124) define a lexical set as any "group of words that share a common element of meaning such as days of the week, or months of the year, or birds, trees, flowers, and metals". What the authors most probably had in mind - but do not state clearly — are lexical sets based on the numerous sense relations distinguished, for example, in the WordNet project (synonymy, hyponymy, or troponymy, etc; cf. Baker, Fillmore and Lowe 1998; and Miller and Fellbaum 1991) or belonging to the same semantic domain/field (e.g., the set of communication verbs: ask, cite, explain, show, tell, babble, bark, bawl, bellow, speak, talk, argue, chat, announce, etc.; cf. Baker and Ruppenhofer 2002 for a discussion).

However, the authors do not explain what constitutes a legitimate "common element of meaning" to determine whether a specific selection of lexical items constitutes a set (i.e. what attribute(s)/value(s) are to be taken as critical for the similarity metric). Given that no restrictions are imposed on the concept of "semantic similarity" nearly any and all words in a lexicon can form a set with any other word. The saying, "similarity lies in the eyes of the beholder", is reiterated as follows by Murphy and Medin (1985: 292):

Any two entities can be arbitrarily similar or dissimilar by changing the criterion of what counts as a relevant attribute. Unless one can specify such criteria, then the claim that categorization (i.e. of belonging to the same lexical set - PHS) is based on attribute matching is almost entirely vacuous.

As Faber and Mairal Usón (1999) argue, linguists have seldom tried to define the term semantic domain in a precise and clearly restricted manner, and the 
same goes for what constitutes a lexical set. Faber and Mairal Usón (1999) do, however, provide a clear method for determining the lexical sets in a language by a systematic bottom-up analysis of the semantic attributes/features used in the dictionary definitions of the lexical items of a language. This method at least provides one with a justified similarity metric for determining the lexical sets of a language.

The problem of providing adequate definitions of lexical set and semantic domain will not be explored here any further. As Faber and Mairal Usón (1999: 79) note, the concepts of semantic fields, lexical domains and thus also lexical sets, have been and still is the object of much imprecision. Of more importance is the fact that the problem of the similarity metric for set membership ties in with that of definitional (in)coherence in as much as "similarity of meaning " is but just one of the many ways in which the lexical items of a set may in fact cohere. Both Faber and Mairal Usón (1999) and Murphy and Medin (1985) therefore put forward the case that lexical coherence is a more apt way of defining lexical sets and that in various linguistic theoretical frameworks a number of constructs (other than the kind of taxonomy underlying the animal set) are used to explain how individual lexical items cohere and therefore constitute a lexical set.

For such a descriptive, often explanatory, model the term lexical conceptual model (LCM) is used in the rest of the article. As used here, LCM is equally general as Kövecses' (2006: 369) term frame (derived from the theoretical framework of frame semantics of Fillmore (cf. Fillmore 2003; and Fillmore and Atkins 1992)), which he defines as follows and links to the various other terms used for such cognitive constructs:

Frames are structured mental representations of an area of human experience (i.e., objects or events) ... Framelike structures have received a variety of names in the literature, including model, idealized cognitive model, domain, script, scene, experiential gestalt, folk theory, and several others. Frames have roles ... that can be instantiated by particular values ... Frames are like schemas in that they sanction more specific instances.

To the list of LCMs identified by Kövecses (2006), one could add folk model, cultural model, expert model, ontology, taxonomy and hierarchy. To these Murphy and Medin (1985) add prototype categories and radial categories (given that deviants from the prototype or prototypical exemplars are also lexicalized). All of these can provide, although they do so in different ways, an analysis/description of the meaning of the members of lexical sets and the nature of their coherence. Obviously, this goes further than "semantic overlap", but includes coherence based on, for example, causality, transformation, contiguity, etc. Fillmore's frames, for example, are defined on the FrameNet website (http://framenet. icsi.berkeley.edu) as "schematic representations of situation types (eating, spying, removing, classifying, etc.) together with lists of the kinds of participants, props, and other conceptual roles that are seen as components of such situa- 
tions". In as much as the participants, props, etc. of such event types are lexicalized (e.g. grocer, client, groceries, credit card, etc.) in a language, the event structure/type (e.g. buying groceries in a store) of the frame provides an explanation of why such words cohere, i.e. they refer to the same frame but have no semantic overlap. (Cf. Murphy and Medin 1985 for an in-depth discussion of how such models explain (as theories about the world) the coherence of members of lexical sets.)

Although the claim is often made that such models represent language users' lexical knowledge, I would like to include under the category of LCMs any systematic description and analysis of the semantic coherence of lexical sets, such as, for example, a linguistically justified analysis of the semantic features of emotion words or of motion verbs and the way in which they cohere, but for which no claims as to their psychological reality are necessarily made (cf. the examples discussed in Section 4).

\subsection{Identifying lexical sets}

As noted, Atkins and Rundell (2008: 128) provide no clear guidelines for the identification of lexical sets. The imprecision with which lexical sets are defined, no doubt adds to this problem. However, once one starts looking at the work being done on semantic fields, domains, sets, ontologies and frames in numerous disciplines, it becomes evident that there is an abundance of resources which lexicographers can tap into (and sometimes also derive their defining attributes/values from):

- analyses of ontological domains (cf., e.g., Jiménez Briones 2007; Jiménez Briones and De Alba 2008; Keil 1979, 1981; Vinson et al. 2003; Vinson and Vigliocco 2002; and Pustejovsky et al. 2006),

- systematic analyses of semantic and syntactic similarities and differences between members of a lexical class and between subclasses of a larger lexical class (cf., e.g., De Clerck et al.'s (To appear) analysis of the verbs of instrument of communication; and Moreno's 2007 analysis of induced motion verbs),

- analyses of the attributes/values used in dictionary definitions and the generation of lexical sets from such analyses "from the bottom up" (cf. e.g., parsing of the attributes/values of the definitions in (machine readable) dictionary texts in Calzolari 1992; Jiménez Briones 2007; Jiménez Briones and De Alba 2008; and De Boni and Manandhar 2002),

- thesauri, such as Roget's Thesaurus (1987),

- large structured electronic dictionaries such as FrameNet and WordNet (cf. Fellbaum 1990; Miller 1990; and Miller and Fellbaum 1991), sometimes enriched with other specialist theories of the mental lexicon (e.g. 
the generative lexicon of Pustejovsky (cf. Pustejovsky 1990) as used in, for example, Liu and Wu 2003 (cf. also De Boni and Manandhar 2002 on how to enrich WordNet with telic information), and

- cultural folk models of a certain knowledge area (e.g. ethnobiological nomenclature, the culture-specific model of the concept SELF which explains the meaning of a large number of self compounds in English (cf. Morillas 1997); and the folk theory of the mind (cf., e.g., D'Andrade 1987; Malle 2005; and Keesing 1987).

Examples are the following:

In Roget's Thesaurus six main conceptual categories are distinguished, each of which denotes a large lexical set and which could be further subdivided into smaller lexical sets: (a) Abstract relations, (b) Space, (c) Matter, (d) Intellect: the exercise of the mind, (e) Volition: the exercise of the will, and (f) Emotion, religion and morality.

In a large database such as WordNet 25, unique beginners are discerned which each identify a large semantic domain/lexical set, some of which can be schematized in a typical hyponymy model as in Figure 1 with the beginners denoting different kinds of tangible things.

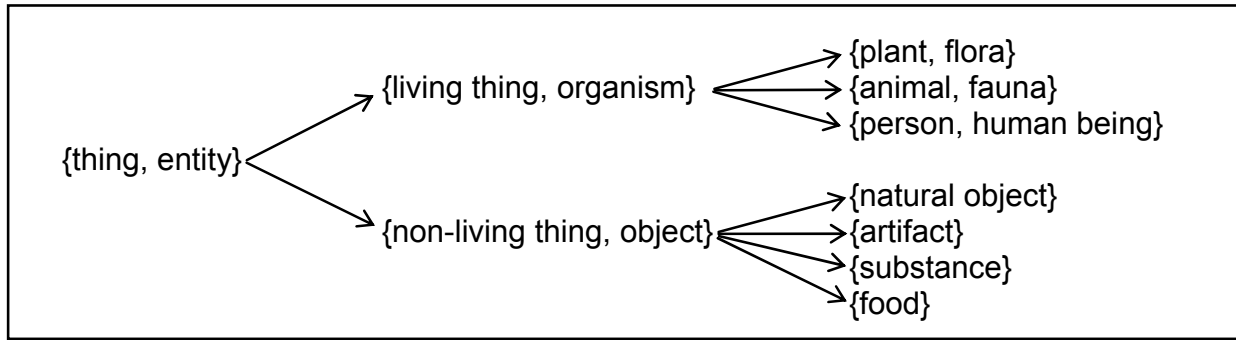

Figure 1: Diagrammatic representation of hypernymic relations among unique beginners denoting different kinds of tangible things (Miller 1990: 252)

In WordNet, verbs are ordered in fifteen semantic domains/lexical sets, for example, verbs of bodily care and functions, change, cognition, communication, emotion, motion, etc. (cf. Fellbaum 1990).

In a more recent contribution, $\mathrm{Liu}$ and $\mathrm{Wu}$ (2003) show how the fourteen frames in FrameNet pertaining to the domain of communication (candidness, commitment, conversation, encoding, gesture, manner, noise, questioning, request, response, statement, volubility, hear and means) can be viewed as subsets of a cognitive system based on the Conduit Metaphor - which gives the necessary coherence to the communication frames. The fourteen frames themselves characterize the distinct background information one has to acquire to understand the senses of the individual verbs of communication where each frame is defined in terms of its prototypical "frame" elements. 
As Faber and Mairal Usón (1999: 82) note, however, in most thesauri and databases such as WordNet and FrameNet, the semantic fields/lexical sets (as ontologies) are established a priori by the compilers so that one has little guarantee that the domains/sets represent inherent cognitive reference points for language users.

Obviously, each of these methods has its own pitfalls in modelling users' lexical knowledge, but they could offer lexicographers valuable assistance in identifying lexical sets.

\subsection{Generating defining attributes and values}

\subsection{1 "Picking the brains of colleagues"}

After relevant lexical sets have been identified, the next issue is how one can identify the relevant attributes and values for the definitions of members of lexical sets. Atkins and Rundell (2008: 127-128) spell out what seems to be a relatively simple procedure where each lexicographer working on a dictionary chooses one word from a specific lexical set (words that are representative of or prototypes of subtypes of a category, e.g. with regard to the animal set lion, unicorn, rat, cow, cat and fox) and then has to compile the richest corpusbased entry they can for that word. In the next step, these entries are compared and collated in a discussion session and a final version of the template entry is drawn up with all possible relevant lexical units included (i.e. the full lexical set) (which, I assume, will be noted on the larger lexical template).

As suggested above, compilation of a definition template is not left only to the lexicographers' intuition about what semantic attributes and features would constitute the meaning of the members of such lexical sets, but it is also to be controlled by current usage working bottom-up from whatever corpus of usage is employed in the compilation of the dictionary (cf. Atkins and Rundell 2008: 264-380). Corpus data as such does not, however, provide one with the relevant attributes/values to use in definition templates. As Atkins and Rundell (2008: 311) note, defining provisional word senses for a lexical item in a set (based as they are on the choice of specific attributes/values) are "the subjective, intuitive part" of the exercise (and more so when it comes to lexical sets organized in taxonomies, hierarchies or ontologies). As they (Atkins and Rundell 2008: 307) admit though, corpus-based data on other linguistic aspects of these lexical items in fact only "complement our intuitions about meaning and underpin an analysis which is as objective and 'scientific' as it reasonably can be, given the slippery and dynamic nature of word meaning".2

No one would probably disagree with the latter part of this quote - it is no easy task formulating functional definitions. But the authors' views also underline that there is no simple way in which one can harvest lexical sets and their defining features for definition templates (such as (3) and (4)) from corpus data (unless the corpus itself consists of definitions of such lexical sets). How- 
ever, there are a number of problems with this approach. Firstly, one cannot assume that a few lexicographers will have direct access to what could/should be taken as the defining features of all possible lexical sets that have to be defined in explanatory dictionaries. Exhaustive lexical knowledge of this kind simply does not reside in a few language users/lexicographers.

Secondly, it remains an open question whether or not there are alternative methodologies available which would also pass the test of being "objective and scientific", however leniently one may use these labels. Identifying lexical sets and their relevant definition attributes/values is a task not only required in lexicography but also in numerous related disciplines which use various kinds of methodologies (equally time-consuming as corpus analysis), such as linguistics, computational linguistics, natural language processing, information design, psycholinguistics, and anthropology. One of these methods is to elicit defining attributes and values for members of lexical sets from language users and then employing clustering techniques to identify the major defining ones (as used, for example, in experimental psychology; cf., e.g., Barsalou 1992; McRae, De Sa and Seidenberg 1997; Vinson et al. 2003; Vinson and Vigliocco 2002; Wu and Barsalou 2009; and Santos et al. To appear).

One of the problems concerning the feature generation methodology, however, becomes apparent if one considers the analysis and coding system for generated features for nouns devised by Barsalou and colleagues (cf. $\mathrm{Wu}$ and Barsalou 2009; and Santos et al. To appear). As they indicate, language users can generate defining features for nouns which denote any aspect of a very complex conceptual system associated with the members of lexical sets something perhaps broader in conceptualization than Fillmore's (2003) frames (cf. Barsalou 2003; Barsalou and Wiemer-Hastings 2005; Wu and Barsalou 2009; and Santos et al. To appear). In the most recent edition of their coding system (personal correspondence Barsalou), the following are listed as relevant feature sets to describe the relationships between a target concept and the features that could be generated in a feature generation exercise. Such a list makes clear what kinds of definitional attributes language users could in principle generate for defining members of lexical sets.

- Taxonomic categories (synonymy, ontological category, superordinate, coordinate, subordinate, individual value of an attribute)

- Situation properties (person, living thing, object, social organization, social artifact, building, spatial relation, time, action, event, manner, function, physical state, social state, quantity)

- Introspective properties (affect/emotion, evaluation, representational state, cognitive operation, contingency, negation (absence of something), quantity)

The question is: Which of these features should be used in designing functional definitions for members of lexical sets, or should all of them be used, given that 
they constitute the elements of the meaning of a lexical unit? On the other hand, many of these possible features for lexical sets are already accommodated in dictionary definitions: relational attributes (synonymy, hyponymy, troponymy, etc.) and decompositional attributes (cf. Miller and Fellbaum 1991 for a summary). In as much as situational attributes overlap with frame ${ }^{3}$ information, Fillmore (2003) presents a proposal as to how such frame information could be incorporated into dictionary definitions (cf. the discussion in Section $3)$.

\subsubsection{Using genus and differentia definitions}

Another way to approach the question of what defining attributes/values are to be used in definitions of members of lexical sets is to use the traditional genus and differentia definition. Atkins and Rundell (2008: 415) in fact view the traditional genus and differentia definition as one of the most useful ones for defining the members of various kinds of lexical sets. Typically this kind of definition type consists of a superordinate term (genus) which places the lexical item in a specific semantic category (lexical set) and additional information (differentia) which indicates what makes the lexical item under consideration unique and in what ways it differs from other members of the same category (its cohyponyms). This definition type is often used not only for certain noun classes, but also for verb classes. The authors illustrate this type of definition with the following example from ODE-2 2003:

convertible ... car (genus) with a folding or detachable roof (differentia)

where the differentiating feature (with a folding or detachable roof) distinguishes convertible from its cohyponyms saloon, estate car or people carrier (cf. Atkins and Rundell 2008: 414).

However, there are problems with this kind of definition and with its use in defining members of lexical sets. It presupposes that dictionary users know what the superordinate/genus car means as this forms part of the meaning of convertible (but is not spelled out), which in turn presupposes that users also have knowledge of the larger hyponymy relation which underlies this definition, viz. convertible $\rightarrow$ car $\rightarrow$ (vehicle $\rightarrow \ldots$ artifact). This follows from the fact that each superordinate term inherits as hyponym some of its defining features from its own superordinate term. In the case of car, one could assume that most dictionary users would possess such knowledge; however, in other taxonomies this may not be the case. In short: The genus only places a lexical item in a semantic category; it does not define the meaning of that category so that the relevant attributes/values in terms of which the lexical items of the category are to be defined are made explicit.

In a more or less "behind the scene" manner, Atkins and Rundell (2008: 418) justify the choice of the defining attributes and values in the ODE-2 2003 
definition of bus by indicating how each of the differentia in fact differentiates a bus from other types of motor vehicle:

(6) bus ... a large motor vehicle carrying passengers by road, typically one serving the public on a fixed route and for a fare.

Their explanation is as follows (Atkins and Rundell 2008: 418):

- a bus is large (and so it is not a car or a taxi)

- it goes by road (so it's not a train)

- it carries passengers (so it's not a truck)

- it typically operates on a fixed route and charges its passengers a fare (which are the features of the prototypical bus and which differentiate it from other bus types that deviate from these prototypical features: school buses, hotel buses, airline buses, staff buses, etc.

The problem is, of course, that the explanatory information, i.e. the explanation for the choice of defining features and the taxonomic structure of the category of vehicles which it refers to, is not typically provided for the dictionary user, although having access to it becomes crucial in acquiring the relevant concept (cf. the discussion in Section 3.1.2).

Thus, it is not always clear precisely by what cohyponyms (and their specific semantic features) a word is differentiated if the rest of the lexical set is not given with a clear indication what their (semantic) features are and precisely how they differ from each other. For example, none of the cohyponyms of convertible or those of the genus car is provided in the definition so that the user in fact does not know from what other types of cars a convertible is distinguished.

These problems also become evident in (1) and (2) and through the definitional templates (3) and (4) (cf. Section 1) in which the attributes/values refer to a larger cognitive structure, namely an ethnobiological animal taxonomy in the case of (1) and (2) and a scientific taxonomy in the case of (3) and (4). In the case of (3) and (4), the domain name/label zoology and the Latin terms of the genus and the species within the definition templates link the lemma to a scientific taxonomy.

A further problem with the genus and differentia definition is that it omits much of the conceptual content/meaning associated with the lexical item that is defined. Examples (1) and (2) are a case in point: The definitions provide the dictionary user with the immediate genus (cat family) and a higher superordinate (animal) plus information that is supposed to differentiate the lexical entries from all others in the lexical set (i.e. they are typical genus and differentia definitions). However, these definitions also omit much information on the semantics of the two lexical items that belong to the same set. Firstly, as already indicated by Atkins and Rundell (2008), they do not provide all the information people have of these animals. The question would therefore be, if someone has 
no idea of what either tiger or lion means, whether or not that person, given these two definitions, will be able to construct accurate concepts of these two lexical items. As Miller (1990: 247) concludes: There is ample support for the inclusion of more, and even so-called "encyclopedic", information into dictionary definitions than merely the genus and one differentiating feature. This approach is evidenced by the NOED definition in (7) (conforming more to the lexical template (3)), which not only provides more information in the main definition, but also incorporates numerous other features in the "encyclopedic" component of the lexical entry.

(7) cat ... a small domesticated carnivorous mammal with soft fur, a short snout, and retractile claws. It is widely kept as a pet or for catching mice, and many breeds have been developed.

- Felis catus, family Felidae (the cat family); probably domesticated in ancient Egypt from the local race of wild cat, and was held in great reverence there. The cat family also includes the ocelot, serval, margay, lynx, and the big cats ... See also BIG CAT.

Neither of the definitions in (1) and (2) contains information about the cohyponyms of the lexical entries which make up the rest of the lexical set. As Miller (1990: 246) notes, dictionary definitions typically point upwards to a superordinate term, but not sideways to coordinate terms or downward to hyponyms. However, this is not general practice as is evidenced in definition (8). In as much as the other information in the definition is supposed to differentiate the lexical headword from other members of the set, it is in fact not clear from which one or more of the rest of the lexical set it is differentiated.

The hierarchies presented in dictionaries are often rather flat (if one considers, for example, that the superordinate structure of a lexical item such as canary is six levels deep: canary $\rightarrow$ finch $\rightarrow$ passerine $\rightarrow$ bird $\rightarrow$ vertebrate $\rightarrow$ animal; cf. Miller 1990: 250). In as much as the meanings of superordinate terms are inherited by those below them, one is given no indication in the definition of what the superordinate lexical items themselves may mean. Here again, the dictionary user would have to search for the meaning of the superordinate terms, if they are indeed entered in the dictionary. For example: In the NOED, there is no separate entry for cat family, but it is simply found as undefined term in the entry for cat. Furthermore, there is a reference to big cat as a separate entry, but without any indication that a difference is made between the small and the big cats and thus that lion and tiger not only belong to the cat family as indicated in (1) and (2), but more specifically to the family of big cats.

(8) big cat ... any of the large members of the cat family, including the lion, tiger, leopard, jaguar, snow leopard, clouded leopard, cheetah, and the puma.

- Panthera and the other genera, family Felidae.

As is the case with this kind of relational information, one has to start searching in the dictionary to find the relevant information, while it could, as will be 
argued below, be made available by incorporating a clickable link in the definition of each of the entries for each of the Felidae lexical items that transports the user to a large LCM where all lexical items are linked in a taxonomy (with definitions for each of the lexical items).

Atkins and Rundell (2008: 416-417) are well aware of some of the other major problems with genus and differentia definitions in so far as they sometimes lead to definitions which attempt to list every possible defining feature to cover every possible instance of the category to which a lexical unit refers, or at other times they result in short and vague definitions in an attempt not to exclude any members of the category. Indeed, finding the balance between brevity in definition, comprehensibility and coverage is not an easy matter, especially if the lexicographer only has the lexicographic definition at his/her disposal to explain the semantics of (members of) lexical sets. As will be argued below, however, linking dictionary definitions with various kinds of dictionary frames, whether internal and external, offer the opportunity to spread out the relevant semantic information in dictionaries, allowing users freedom to access as much information as possible for whatever purpose they consult an explanatory dictionary.

\subsection{The structure of definitions of lexical sets}

In addition to the question of what defining attributes/values to select for the definitions of members of lexical sets, there is also the question of the order in which the chosen attributes/values should be presented. Is there some kind of "internal logic" in the order in which the defining attributes/values of definitions of members of lexical sets are given, or would it have no functional consequences if some random order was chosen?

Atkins and Rundell (2008: 439) address this issue of the ordering of the attributes FORM (what a thing looks like, is made of) and FUNCTION (what is it used for) as in the definition of artifacts such as windmill. No clear rules for the ordering of the attributes are given, but they present Bolinger's (1965: 572) suggestion that the first attribute chosen should relate "the unknown to the known" (Atkins and Rundell 2008: 439). Consequently they suggest that in a dictionary aimed at users in industrialized countries where windmills are rarely used for their original function of crushing grain, the first attribute for windmill should be its form (as windmills are familiar structures with a distinctive form) (cf. (9) for the definition from ODE-2 2003):

(9) windmill ... a building with sails or vanes that turn in the wind (FORM) and generate power to grind corn into flour (FUNCTION).

On the other hand, for the definition of watering can, the criterion is how much of the definition one would have to read before being able to identify the definiendum. According to this criterion, they would prioritize definition (11) of watering can over definition (10). However, there is in my opinion no way to 
choose in this regard between (11) and (12) where the order of the attributes are reversed, but both are, of course, very short definitions.

(10) watering can ... a container with a tube that ends in a wide mouth with many small holes (FORM) which is used for watering things, usually plants (FUNCTION).

watering can ... a container used for pouring water on plants (FUNCTION), with a handle and a long spout (FORM).

watering can ... a container with a handle and a long spout (FORM), used for pouring water on plants (FUNCTION).

As a guideline, Atkins and Rundell (2008: 440) further note, firstly, that if form and function are presented in optimal order, the chances are increased that users may "log off" before the end of the definition, and secondly, that form is a less reliable indicator of the meaning of a lexical item "since the shape and construction of things tend to vary but their function is usually stable".

However, form and function are only two of the many possible attributes that could be used in defining the members of lexical sets. For the description of nouns (specifically artefacts such as windmills and watering cans), a more justified set of definitional attributes is proposed by Pustejovsky for his generative lexicon. Artefacts can, for example, be defined in terms of any one or more of the following attributes:

- Constitutive relationships (the relation between an object and its constitute parts, e.g. material, weight, parts and component elements - attributes which could also be regarded to fall under FORM)

- Formal relationships (that which distinguishes an object within a larger domain, e.g. orientation, magnitude, shape, dimensionality, colour, position)

- Telic relationship (the purpose or function of an object, e.g. the purpose an agent has in performing an act or the built-in function or aim which specifies certain activities - attributes that would fall under FUNCTION)

- Agentive relationships (factors involved in the origin or "bringing about" of an object, e.g. creator, artifact, natural kind, causal chain)

(Cf. also Bougarev and Pustejovsky 1990; De Boni and Manandhar 2002; Calzolari et al. 2005; and Cimiano and Wenderoth 2007.) These attributes play a crucial role in the semantics of the compounds formed with such nouns (as heads) and their polysemy. Once again, there is no strict ordering of the attributes in definitions utilizing the telic structure.

Generally speaking though, language users associate richer conceptual structures with lexical items, and thus with the members of lexical sets. For 
example, nouns which fall within the basic level in any hierarchy/taxonomy also denote things with which people have sensory motor interaction (form: perception, taste, touch, smell, sound; function: motor interaction). Language users thus have extensive conceptual knowledge (attributes) of such entities, but there is clearly no set order for such attributes and neither is there one attribute which dominates in all contexts.

As far as could be ascertained, no research has been forthcoming on the optimal ordering of the defining attributes of lexical (sub)sets. One way to proceed would be to work from the definitions for the members of lexical subsets and ascertain what attributes/values are commonly used and what ordering patterns occur before experimentally testing what ordering(s) is (are) optimal for which kinds of users, dictionary types and dictionary functions.

\section{Using lexical conceptual models in defining members of lexical sets - functionalist considerations ${ }^{4}$}

Most of the problems related to the definition of members of lexical sets discussed above can be addressed by enriching their definitions in electronic dictionaries with linked/clickable LCMs.

Fillmore (2003) provides a convincing argument for the inclusion in electronic monolingual learners' dictionaries of "double-decker" definitions for sets of lexical items that refer to the same LCM, in this case, frame. A double-decker definition contains two parts: one that provides a semantic explanation (definition) of the meaning of the lexical item, and one which provides a (clickable) link to a frame of structured background information which dictionary users could need to understand not only the semantic explanation of the lexical item under consideration but also the explanations/definitions provided for the other lexical items in a lexical set. The following are a few examples:

Most dictionary definitions for the lexical set $i d$, ego, and superego only become transparent if they are interpreted within the frame of Freud's theory of primitive psychic energies and the manner of their control and modification in the maturing individual (Fillmore 2003: 272-275). Most definitions of the lexical items that name the days of the week only make sense (for non-Western dictionary users) if they are defined against the background frame of the Western calendric concept. As Fillmore (2003: 267) notes: "A dictionary definition that identifies Wednesday merely as the middle day of the week is sufficient only when the full background (i.e. frame of the calendric concept - PHS) can be taken for granted." Likewise, definitions of heaven, hell, purgatory, and limbo can only be understood against the folk theory of Catholic eschatology (cf. Fillmore 2003: 279-283). Such frames have to be provided if, as Fillmore (2003: 284) says, " 'outsiders' are to end up having the same understandings as the people who live within these frames".

In general, Fillmore's (2003) frames, like schemas, scripts, image schemas (cf. Fillmore 2003: 288), Idealized Cognitive Models (ICMs) (cf. Lakoff 1987) 
and cognitive cultural models (cf. Morillas 1997) are encyclopedic knowledge structures or conceptualizations underlying the meaning of sets of lexical items that in some way appeal to such structures and that need to be accessed (either in your own brain if "you live the frame", or some encyclopedic work if you do not) to make sense of or to understand the dictionary definitions of the lexical items in such sets. By explicating such mental models, learners' dictionaries can thus give dictionary users insight into the semantic coherence which sets of lexical items with the same frame have - something that the traditional, printed, alphabetically organized learners' dictionary for the most part cannot.

Two of the advantages of using such frames are that the LCM provides the attributes/values to be used in definitions of members of a lexical set, and that not all the attributes/values have to be included in the definition of each member of a set. Members of lexical sets are all linked to the same frame. Thus the relevant background information is provided only once and dictionary users can decide whether or not they have to access the frame for more information to comprehend a definition or not. Another advantage is that the user is not obliged to start an extensive look-up exercise as in a printed dictionary to find the relevant information, even if it is included in the same dictionary.

The inclusion of LCMs in electronic learners' dictionaries is also justified by functional considerations. With regard to their functions, Bergenholtz and Tarp (2003) distinguish between the knowledge and communication functions of a dictionary (cf. also Gouws and Prinsloo 2005). Knowledge functions relate to situations where users for one reason or another want to obtain additional information on some topic, e.g. general cultural and encyclopedic information, specialized information regarding a scientific discipline (e.g. biology, geology etc.) or information about a specific language related to the language-learning process (for example the learning of a foreign language).

For the communication functions, dictionaries have to provide users with the necessary data for the following communication tasks:

- text production in the native or in a foreign language,

- text reception in the native or in a foreign language, and

- translation of texts from the native language to a foreign language and vice versa.

An adequate understanding of the meaning of members of lexical sets is a prerequisite for a dictionary to be able to assist the user in any of the knowledge and communication functions listed above. In so far as linked LCMs can assist in this regard, their inclusion is completely justified.

Fillmore (2003) refers to such definitions as "lexico-encyclopedic" definitions. As the term clearly suggests, Fillmore, as is the case in most cognitive semantic theories, makes no principled distinction between so-called linguistic and encyclopedic lexical meaning. Likewise, dictionaries linked with LCMs can be considered lexical knowledge databases instead of mere lexical/lexico- 
graphic databases. Such additions are necessary to support the multiple functions of learner's dictionaries.

\subsection{Providing information for the knowledge functions}

\subsubsection{Cultural and encyclopedic information, specialized information re- garding a scientific discipline}

The first argument for the inclusion of LCMs in dictionaries is provided by the knowledge function. This requires that dictionaries should provide users with general cultural and encyclopedic information, specialized information regarding a scientific discipline (biology, geology etc.) or information about a specific language related to the language-learning process (for example the learning of a foreign language).

Although Bergenholtz and Tarp (2003) most probably had in mind that these three categories of information should be provided in different kinds of dictionaries or lexicographic resources (i.e. encyclopedias, subject dictionaries and linguistic dictionaries), information from the first two traditional resources (encyclopedias and subject dictionaries) may be required as linked LCMs in traditional dictionaries, as the examples discussed in Section 1 and Section 2 clearly indicate.

In as much as specific cultural models, encyclopedic and subject-specific information explain the meaning of specific lexical items or terms which have found their way into the general vocabulary, the definitions of such lexical items will have to be supplemented with their associated cultural, encyclopedic or subject LCMs. Fillmore's (2003) example of how the lexical set consisting of $i d$, ego and superego requires access to an LCM in which Freud's theory of the human psyche is explicated is an example of such a subject-specific LCM required as link in a linguistic dictionary. Any ethnobiological model of fauna and flora, on the other hand, are examples of folk models which explicate the meaning of the large lexical sets denoting plants and animals.

Cultural specific models also explain the meaning of large lexical sets. One example includes the Western/American folk model of mind underlying the meaning of lexical sets related to the processes of thinking, intention, desires and emotion (cf., e.g., D'Andrade 1987; and Keesing 1987). Another example is the very complex LCM of the self which underlies an extensive set of lexical items, especially compounds with self- in English (cf. Morillas 1997). Many common nouns and verbs, even some proper nouns, which are headwords in encyclopedias also appear in monolingual dictionaries, and, once a strict distinction between linguistic and encyclopedic information is no longer kept, linking the two by way of lexicographic definitions and LCMs is a natural second step. 


\subsubsection{Acquisition of a foreign language}

In providing information for users for acquiring a foreign language, the lexicographer specifically has the task (in designing the monolingual explanatory dictionary), as Fillmore (2003: 284) notes,

to make explicit the background of beliefs, experiences, practices, institutions, or ready-made conceptualizations available to the speakers of the language as the necessary underpinnings of the way they speak and the ways they "think for speaking".

One of the important aspects of learning a foreign language is learning such lexical sets. There is ample psycholinguistic evidence that many of these sets are relationally structured (cf., e.g., Fellbaum 1990; Miller 1990; and Miller and Fellbaum 1991). For example, as in the case of the animal words discussed in Section 1, many lexical sets in any one language are linked via hyponymy relationships. The acquisition of such hyponymy relations in a language are an important aspect of the learning of the lexicon of such a language (cf. Crossley, Salsbury and McNamara 2009). Building such hyponymy lexical relations is an essential aspect of vocabulary acquisition in a language either as one's mother tongue or as a foreign language (cf. Li 2009: 636; however, also see Nation 2000). Linking the members of lexical sets to such taxonomies or hypernymic models is therefore a prerequisite in monolingual explanatory dictionaries which aim to satisfy the (lexical semantic) information needs of language learners.

The lexical sets associated with Fillmore's type of frames are also often used as the basis for constructing learning materials for L2 lexical acquisition, for example, going to a restaurant, the market, going shopping, visiting particular sights, etc. A step further is the production of bilingual dictionaries based on such frames. One such dictionary in the making is the English-Hungarian dictionary of Kövecses (personal communication) with entries such as the following from the musical concert frame. See example (13):

(13) karmester conductor A zenekart a karmester vezényli. The orchestra is conducted/directed by the conductor. FOGALOM: A zenekar (orchestra) különböző hangszereken (instruments) játszó zenészekból (musicians) áll. A zenekart a karmester (conductor) vezényli (conduct, direct). A zenekar elöször hangol (tune (sg) up), majd a karmester utasítására játszani (play) kezd. A karmester a hangmesteri pálca (baton) segítségével vezényel a dobogóról (rostrum, podium).

Of course, language learners need more information on the conceptual structure of members of lexical sets to acquire these lexical items and to be able to use them in production tasks. Including LCMs such as those discussed in 3.1.1 and 3.1.2 in electronic dictionaries will therefore also support the language acquisition function. 


\subsection{Providing information for the communication functions}

What kind of LCMs is required for comprehension, production and translation? Because of the limitations of space, the first and last of these will be discussed.

Elman (2009) provides numerous examples of how language users' knowledge of event structures (equivalent to Fillmore's frames) ${ }^{5}$ are activated in the processing/comprehension of texts and how this knowledge is used to predict the meaning of the rest of a sentence and to disambiguate polysemous words/sentence fragments. For example, surgeon in the sentence fragment The surgeon ... activates the hospital-operation LCM/frame, where such an LCM would then list all the lexical items (and their associated meanings) which denote the agents, location, procedures, etc., involving the prototypical event of doing an operation in a hospital. Such an LCM can be primed by any of the members of the lexical set (e.g. operating table) and such LCMs, once activated, make it possible to access knowledge of the rest of the LCM, making it unnecessary to repeat much of the information contained in the LCM in normal discourse. However, without knowledge of such an LCM, of which not all relevant conceptual content is provided in a prototypical lexicographic definition, one would make very little sense of what people are talking about. As Elman (2009: 572) notes: "Events play a major role in organizing our experience. Event knowledge is used to drive inference, to access memory, and affects the categories we construct." 6 (Cf. also Shipley and Zacks 2008 on the role of event knowledge in perception, action and cognition.)

The functionalist considerations given above in fact just add to some of the criteria Atkins and Rundell (2008: 412-413) spell out as good definitional practice, i.e. definitions

- must be intelligible (which would include, among others, that a user should not have to consult another definition to understand the one being looked up),

- should supply enough information to enable the user to understand the word in the context it is encountered,

- $\quad$ enable the user to interpret the word in any new context (so that it enters the user's passive vocabulary), and

- enable the user to use the word correctly in a new context (so that it enters the user's active vocabulary).

\section{Designing LCMs}

How should the proposed LCMs look like in order for them to be linked to members of lexical sets? In most cases, such as the FrameNet and WordNet ontologies and those devised for use in natural language processing applica- 
tions, they contain much of the information needed for the design of LCMs. However, the presentation of the data is usually not user-friendly and often not easily comprehended given the often arbitrary symbols used or the format chosen to encode attributes, values, relations, etc.

On the other hand, other analyses of lexical sets that avoid these problems are more directly usable. One such example is the lexical templates designed as part of the Lexical Construction Model (cf. http://www.lexicom.es) for the category of anger verbs (Jiménez Briones 2007) and happiness verbs (Jiménez Briones and De Alba 2008). Both the English and Spanish lexicons of LEXICOM are organized paradigmatically and syntagmatically into a series of coherent semantic classes/lexical sets (e.g. EXISTENCE CHANGE, POSSESSION, SPEECH, EMOTION, etc.) which are derived by means of a process of exhaustive semantic factorization, working upwards from various dictionary entries (such as those of LDOCE, CIDE and COBUILD) of the possible predicates belonging to each class (for example 250 feeling verbs have been identified, belonging to various subclasses). For every verb a genus (the nuclear meaning) and differentia (adverbial modification (e.g. Manner, Reason, Degree) or other distinguishing features (e.g. selectional restrictions), pragmatic or register features (formal, literary, emphatic) are provided. Furthermore, definitions are encoded in Wierzbicka's Natural Language Semantics, making the definitions themselves very accessible, although its limited nature often does not allow one to express the differences in meaning between members of lexical sets all too clearly.

The usability of these analyses to function as LCMs for human dictionaries is clear from Jiménez Briones's (2007: 2) presentation of anger verbs (cf. Table 1).

to cause somebody to feel emotional aversion [anger]

1. anger: to cause somebody to feel anger.

1.1. annoy: to anger somebody a little.

1.1.1 vex: to annoy somebody, causing them to feel puzzled. [Old-fashioned].

1.1.2 displease: annoy somebody, causing them to feel displeasure/inconvenience [Fml.].

1.1.3 irk: to annoy somebody, causing them to feel disgust [Infml.].

1.1.4 nettle: to annoy somebody for only a short time.

1.1.5 gall: to annoy somebody by disappointing them.

1.1.6 bug: to annoy somebody so that they cannot stop thinking about it [Infml.].

1.1.7 irritate: to annoy somebody, causing them to feel irritated.

1.2. provoke: to anger somebody deliberately by trying to make them act aggressively.

1.2.1 needle: to provoke somebody deliberately by repeated criticism [Infml.].

1.3. antagonize: to anger somebody by making them feel hostile towards you.

1.4. rile: to anger somebody very much [Infml.].

1.5. exasperate: to anger somebody very much, causing them to become impatient or frustrated.

1.6. outrage: to anger somebody extremely, causing them to feel offended or shocked.

1.7. incense: to anger somebody extremely, causing them to feel indignation. 
1.8. enrage: to anger somebody extremely, causing them to lose self-control.

1.9. infuriate: to anger somebody extremely, causing them to be furious.

1.10. madden: to anger somebody extremely, causing them to figuratively become mad.

Table 1: Paradigmatic organization of anger verbs (Jiménez Briones 2007: 2)

All members of the lexical set of anger words can thus be linked to this LCM which would make it clear to the dictionary user precisely what lexical items make up the set, and how they share attributes and in what ways they differ from the rest of the members of the set. (Cf. also Faber and Mairal Usón's 1999: 109-115 analysis of the semantics of the manner of walking verbs and Jiménes Briones' 2007 analysis of verbs of feeling.)

\section{Conclusion}

As Fillmore (2003) notes, technological advances have made it possible to construct lexical databases in which various kinds of text types (dictionaries, encyclopedias, etc.) can be incorporated and linked in numerous ways to enhance the functionality of such reference works. However, he stresses that there is still an urgent need to develop theories and models of lexical conceptual knowledge to support the design of such databases. The development of Frame Semantics and the proposal on how to link frames to the lexicographic description of lexical sets in electronic dictionaries is an important step in this direction. The proposal to link definitions of lexical sets with a larger category of lexical conceptual models is an attempt to take Fillmore's (2003) a small step further. Obviously, much more research is needed on a number of topics, such as the definition of lexical sets, how to generate their definitional attributes and values, and the best designs for LCMs to optimize their functionality in dictionaries of different types and for different kinds of dictionary users.

\section{Endnotes}

1. This is not to say that these two problems occur in all dictionaries and to the same degree (cf., e.g., the dictionary entry (8)).

2. Hanks (2000: 211) sums it up as follows: "There is no direct route from the corpus to the meaning. Corpus linguists sometimes speak as if interpretations spring fully fledged, untouched by the human hand, from the corpus. They don't. The corpus contains traces of meaning events; the dictionary contains lists of meaning potentials."

3. On the FrameNet website (http://framenet.icsi.berkeley.edu) frames are defined as: "Schematic representations of situation types (eating, spying, removing, classifying, etc.) together with lists of the kinds of participants, props, and other conceptual roles that are seen as components of such situations. The semantic arguments of a predicating word correspond to what we call the frame elements of the frame associated with that word."

4. Although much has been made in the literature about the fact that the design of dictionaries should be determined by their intended users and their major functions, very little research 
has in fact been forthcoming in which the results of theory-driven empirical research on these functions are systematically and comprehensively linked with each and every design feature of the various kinds of dictionary types and dictionary users.

5. Elman (2009: 572) defines an event as "a set of participants, activities, and outcomes that are bound together by causal interrelatedness".

6. Given the critical role event knowledge plays in comprehension, Elman (2009) argues, ironically, for a grammar without a lexicon, or at most one in which lexical entries consist only of a lexical headword with a pointer to the event frame that explains the meaning and use of the lexical headword. The same line of argument for a minimalist lexicon is followed in Carter (1997). In Barsalou's semantics of situatedness, a network architecture for lexical knowledge is proposed in which linguistic forms such as lexical items constitute associative networks, but in which these forms are linked to all the defining features of event-like structures.

\section{References}

\section{Dictionaries}

CIDE: Cambridge International Dictionary of English. Cambridge: Cambridge University Press. COBUILD: Collins COBUILD English Dictionary. London: HarperCollins.

LDOCE: Longman Dictionary of Contemporary English. Harlow: Pearson Education. NOED: The New Oxford English Dictionary. Oxford: Oxford University Press. ODE-2: Oxford Dictionary of English. Second Edition. Oxford: Oxford University Press.

Rogets Thesaurus: Roget's Thesaurus of English Words and Phrases. Harmondsworth: Penguin Books.

\section{Other sources}

Atkins, B.T.S. and M. Rundell. 2008. The Oxford Guide to Practical Lexicography. Oxford: Oxford University Press.

Baker, C., C. Fillmore and J. Lowe. 1998. The Berkeley FrameNet Project. Proceedings of the COLING-ACL, Montreal, Canada. http://framenet.icsi.berkeley.edu/index.php?option=com_contentandtask=viewandid $=39$ anditemid $=42$.

Baker, C. and J. Ruppenhofer. 2002. FrameNet's Frame vs. Levin's Verb Classes. Larson, J. and M. Paster (Eds.). 2002. Proceedings of the 28th Annual Meeting of the Berkeley Linguistics Society: 2738. http://framenet.icsi.berkeley.edu/index.php?option=com_contentandtask=viewandid= 39andItemid $=42$.

Barsalou, L. 1992. Frames, Concepts and Conceptual Fields. Lehrer, A. and E. Kittay (Eds.). 1992: 21-75.

Barsalou, L. 2003. Situated Simulation in the Human Conceptual System. Language and Cognitive Processes 18(5-6): 513-562.

Barsalou, L. and K. Wiemer-Hastings. 2005. Situating Abstract Concepts. Pecher, D. and R. Zwaan (Eds.). 2005. Grounding Cognition: The Role of Perception and Action in Memory, Language and Thought: 129-163. New York: Cambridge University Press.

Bergenholtz, H. and S. Tarp. 2003. Two Opposing Theories: On H.E. Wiegand's Recent Discovery of Lexicographic Functions. Hermes, Journal of Linguistics 31: 171-196.

Boguraev, B. and J. Pustejovsky. 1990. Lexical Ambiguity and the Role of Knowledge Representation in Lexicon Design. Karlgren, H. (Ed.). 1990. Proceedings of the 13th Conference on Computa- 
tional Linguistics. Volume 2: 36-41. http://www.aclweb.org/anthology-new/C/C90/C902007.pdf.

Bolinger, D. 1965. The Atomization of Meaning. Language 41: 555-573.

Calzolari, N. 1992. Acquiring and Representing Semantic Information in a Lexical Knowledge Base. Lecture Notes in Computer Science 627: 235-243.

Calzolari, N., C. Fillmore, R. Grishman, N. Ide, A. Lenci, C. MacLeod and A. Zampolli. 2005. Towards Best Practice for Multiword Expressions in Computational Lexicons. http://gandalf. aksis.uib.no/lrec2002/pdf/259.pdf.

Carter, R. 1997. Lexical Knowledge, Conceptual Knowledge, and Generativity. Sémiotiques 13: 4164.

Cimiano, P. and J. Wenderoth. 2007. Automatic Acquisition of Ranked Qualia Structures from the Web. Proceedings of the 45th Annual Meeting of the Association for Computational Linguistics: 888895.

Crossley, S., T. Salsbury and D. McNamara. 2009. Measuring L2 Lexical Growth Using Hypernymic Relations. Language Learning 59(2): 307-334.

D'Andrade, R. 1987. A Folk Model of the Mind. Holland, D. and N. Quinn (Eds.). 1987: 112-148.

De Boni, M. and S. Manandhar. 2002. Automated Discovery of Telic Relations for WordNet. Proceedings of the 1st International WordNet Conference, India.

De Clerck, B., F. Verroens, D. Willems and T. Colleman. To appear. The Syntactic Flexibility of (Recent) Verbs of Instrument of Communication: A Corpus-based Study. Functions of Language.

Elman, J. 2009. On the Meaning of Words and Dinosaur Bones: Lexical Knowledge without a Lexicon. Cognitive Science 33: 547-582.

Faber, P. and R. Mairal Usón. 1999. Constructing a Lexicon of English Verbs. Berlin: Mouton.

Fellbaum, C. 1990. English Verbs as a Semantic Net. International Journal of Lexicography 3(4): 278301.

Fillmore, C. 2003. Double-decker Definitions: The Role of Frames in Meaning Explanations. Sign Language Studies 3(3): 263-295.

Fillmore, C. and B. Atkins. 1992. Toward a Frame-based Lexicon: The Semantics of RISK and its Neighbors. Lehrer, A. and E. Kittay (Eds.). 1992: 75-102.

Gouws, R.H. and D.J. Prinsloo. 2005. Principles and Practice of South African Lexicography. Stellenbosch: Sun PReSS.

Hanks, P. 2000. Do Word Meanings Exist? Computers and the Humanities 34: 205-215. (Also included in Fontenelle, T. (Ed.). 2008. Practical Lexicography. A Reader: 125-134. Oxford: Oxford University Press.)

Holland, D. and N. Quinn. 1987. Cultural Models in Language and Thought. Cambridge: University of Cambridge Press.

Jiménez Briones, R. 2007. The Lexical Representation of the English Verbs of Feeling within the Lexical Constructional Model. Paper read at the 40th Annual Meeting of the Societas Linguistica Europaea, University of Joensuu, Finland, August 29-September 1, 2007. http:// www.lexicom.es/drupa/files/RocioJimenez_SLE2007.pdf

Jiménez Briones, R. and B. De Alba. 2008. Lexical Presentation within the Lexical Construction Model: An Analysis of Verbs of happiness and happening. RESLAi 21: 129-146.

Keesing, R. 1987. Models, "Folk" and "Cultural". Paradigms Regained. Holland, D. and N. Quinn (Eds.). 1987: 369-393. 
Keil, F. 1979. Semantic and Conceptual Development: An Ontological Perspective. Cambridge, MA: Harvard University Press.

Keil, F. 1981. Constraints on Knowledge and Cognitive Development. Psychological Review 88: 197227.

Kövecses, Z. 2006. Language, Mind, and Culture. A Practical Introduction. Oxford: Oxford University Press.

Lehrer, A. and E. Kittay (Eds.). 1992. Frames, Fields, and Contrasts. New Essays in Semantic and Lexical Organization. Hillsdale, NJ: Lawrence Erlbaum.

Li, P. 2009. Lexical Organization and Competition in First and Second Languages: Computational and Neural Mechanisms. Cognitive Science 33: 629-664.

Liu, M. and Y. Wu. 2003. Beyond Frame Semantics: Insight from Mandarin Verbs of Communication. http://www.fl.nctu.edu.tw/ mliu/papers/Beyond\%20Frame\%20Semantics_Insight $\%$ 20from $\% 20$ Mandarin\%20Verbs $\% 20$ of $\% 20$ Communication.pdf.

Malle, B. 2005. Folk Theory of Mind: Conceptual Foundations of Social Cognition. http:// cogprints.org/3315/.

McRae, K., V. De Sa and M. Seidenberg. 1997. On the Nature and Scope of Featural Representations of Word Meaning. Journal of Experimental Psychology. General 126(2): 99-130.

Miller, G. 1990. Nouns in WordNet: A Lexical Inheritance System. International Journal of Lexicography 3(4): 245-264.

Miller, G. and C. Fellbaum. 1991. Semantic Networks of English. Cognition 41: 197-229.

Moreno, A. 2007. A Semantic Analysis of Universal and Idiosyncratic Features of Induced Motion Verbs: From the Perspective of Language Typology. Journal of Universal Language 8: 23-49.

Morillas, J. 1997. The Cultural Cognitive Model: A Programmatic Approach. Cuadernos de Filologia Inglesa 612: 53-63.

Murphy, G. and D. Medin. 1985. The Role of Theories in Conceptual Coherence. Psychological Review 92(3): 289-316.

Nation, P. 2000. Learning Vocabulary in Lexical Sets: Dangers and Guidelines. Tesol Journal 9(2): 610.

Pustejovsky, J. 1990. The Generative Lexicon. Computational Linguistics 14(4). http://acl.ldc.upenn. edu/J/J91/J91-4003.pdf.

Pustejovsky, J. 1991. The Syntax of the Event Structure. Cognition 41: 47-81.

Pustejovsky, J., C. Havasi, J. Littman, A. Rumshisky and M. Verhagen. 2006. Towards a Generative Lexical Resource: The Brandeis Semantic Ontology. http://www.cs.brandeis.edu/ $\sim$ arum/publications/lrec-bso.pdf.

Santos, A., S.E. Chaigneau, W.K. Simmons and L.W. Barsalou. To appear. Property Generation Reflects Word Association and Situated Simulation. Language and Cognition.

Shipley, T. and J. Zacks (Eds.). 2008. Understanding Events: From Perception to Action. Oxford: Oxford University Press.

Vinson, D. and G. Vigliocco. 2002. A Semantic Analysis of Noun-Verb Dissociation in Aphasia. Journal of Neurolinguistics 15: 317-351.

Vinson, D., G. Vigliocco, S. Cappa and S. Siri. 2003. The Breakdown of Semantic Knowledge: Insights from a Statistical Model of Meaning Representation. Brain and Language 86: 347-365.

Wu, L.-L. and L. Barsalou. 2009. Perceptual Simulation in Conceptual Combination: Evidence from Property Generation. Acta Psychologica 132: 173-189. 